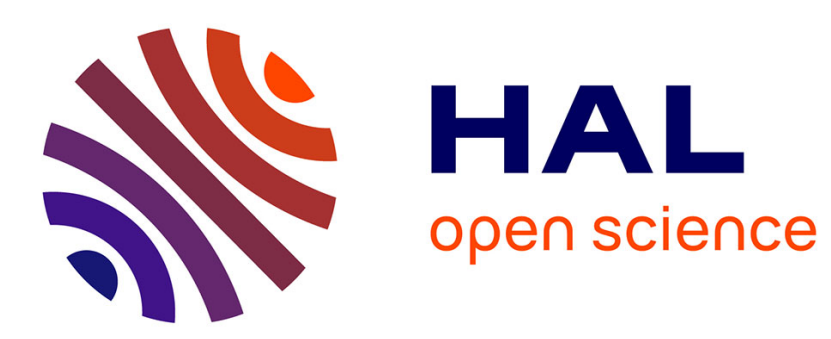

\title{
POLARIZED LITHIUM-6 BEAM AT SATURNE
}

\author{
P. Chamouard, A. Courtois, J. Faure, R. Gobin, J. Lagniel, J. Lemaire, P. \\ Leroy, B. Visentin, P. Zupranski
}

\section{To cite this version:}

P. Chamouard, A. Courtois, J. Faure, R. Gobin, J. Lagniel, et al.. POLARIZED LITHIUM-

6 BEAM AT SATURNE. Journal de Physique Colloques, 1990, 51 (C6), pp.C6-565-C6-568. 10.1051/jphyscol:1990674 . jpa-00230944

\section{HAL Id: jpa-00230944 https://hal.science/jpa-00230944}

Submitted on 1 Jan 1990

HAL is a multi-disciplinary open access archive for the deposit and dissemination of scientific research documents, whether they are published or not. The documents may come from teaching and research institutions in France or abroad, or from public or private research centers.
L'archive ouverte pluridisciplinaire HAL, est destinée au dépôt et à la diffusion de documents scientifiques de niveau recherche, publiés ou non, émanant des établissements d'enseignement et de recherche français ou étrangers, des laboratoires publics ou privés. 
POLARIZED LITHIUM-6 BEAM AT SATURNE

P.A. CHAMOUARD, A. COURTOIS, J. FAURE, R. GOBIN, J.M. LAGNIEL, J.I. LEMAIRE, P.A. LEROY, B. VISENTIN and P. ZUPRANSKI

LNS, CEN-Saclay, F-91191 Gif sur Yvette Cedex, France

Abstract: The SATURNE synchrotron facility is now equipped with a polarized Lithium-6 ion source for nuclear physics experiments. The source is an arrangement of a conventional polarized atomic beam and a ionizer injecting the $\mathrm{Li}^{1+}$ ions into the Saturne EBIS, DIONÉ. The $\mathrm{Li}^{1+}$ ions are trapped and ionized inside the EBIS electron beam. After acceleration through the RFQ, $\mathrm{Li}^{3+}$ ions are injected into MIMAS.

\section{Polarized atomic beam.}

The atomic beam emerges from an oven and the polarization is obtained by means of a conventional Stern-Gerlach magnet followed by three RF transitions. The device is similar to the Heidelberg source ${ }^{1}$ ) and some parts ( oven, sextupole magnet and RF cavities ) are spare elements from Heidelberg Laboratory. All these parts have been assembled and adapted to the technical requirements of an EBIS environment.

\section{ui $^{1+}$ beam ionizer.}

The polarized atomic beam is ionized on a hot oxidized tungsten strip. The oxygen partial pressure is about $10^{-6}$ torr. The tungsten surface is inclined at $90^{\circ}$ to the atomic and ionic beam axis. The ions are extracted by an uniform electrical field and the extracting voltage is 10 kV. A 460 gauss uniform magnetic field, parallel to the electrical field, defines the polarization direction during the surface ionization.

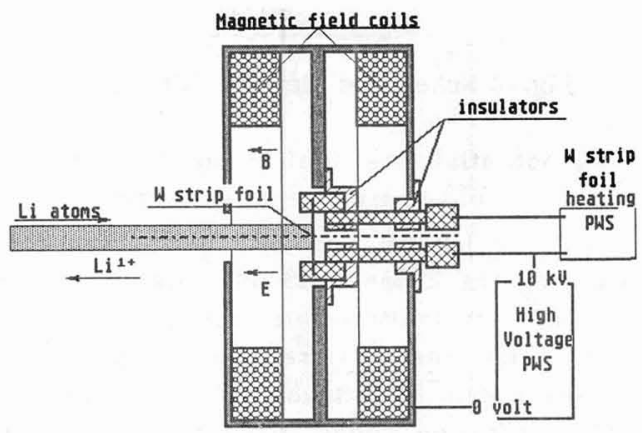

Fig. 1 Lithium lonizer The tungsten strip foil is directly heated and biased at $10 \mathrm{kV}$.

The emittance of the ions beam is a very important parameter for the injection in DIONÉ and has two main origins :

- the transverse energy due to the thermal energy of ions at the strip temperature (above $1000^{\circ} \mathrm{C}$ ). The emittance is given by :

$$
E_{x}=\frac{\pi r}{c}(k T / m)^{1 / 2}
$$

and, using ionizer parameters, one comes to $1.510^{-7} \mathrm{~m} . \mathrm{rad}$ (normalized). 
- the magnetic field. In order to define the polarization, this field is uniform. The emittance is given by the flux variation inside the beam at the ionizer exit :

$$
\mathbf{E}_{\mathbf{x}}=\frac{\eta \mathbf{B}}{2} \frac{\pi \mathbf{r}^{2}}{\mathbf{c}} \varepsilon \text { and, using the ionizer parameters, }
$$

it results on $10^{-7} \mathrm{~m}$. rad. (normalized).

Therefore, the total expected emittance is 2 or $310^{-7} \mathrm{~m} . \mathrm{rad}$ (normalized), suitable value for injecting into DIONÉ.

\section{Ionization process inside DIONE}

For a few $\mu \mathrm{A} \mathrm{Li}^{1+}$ beam intensity a conventional ionizer would have delivered a few $\mathrm{nA}$ of $\mathrm{Li}^{3+}$ in $\mathrm{DC}$ mode.

DIONE, an EBIS ion source, is usualy used to produce highly charged heavy ions $\left(\mathrm{Kr}^{30+}\right.$, for instance). The ionization process involved has been described in detail previously ${ }^{2)}$. In brief; an electron gun emits a stream of electrons wich are focused and conducted through a series of cryogenically cooled drift tubes by the strong magnetic field (STs) of a superconducting solenoid.

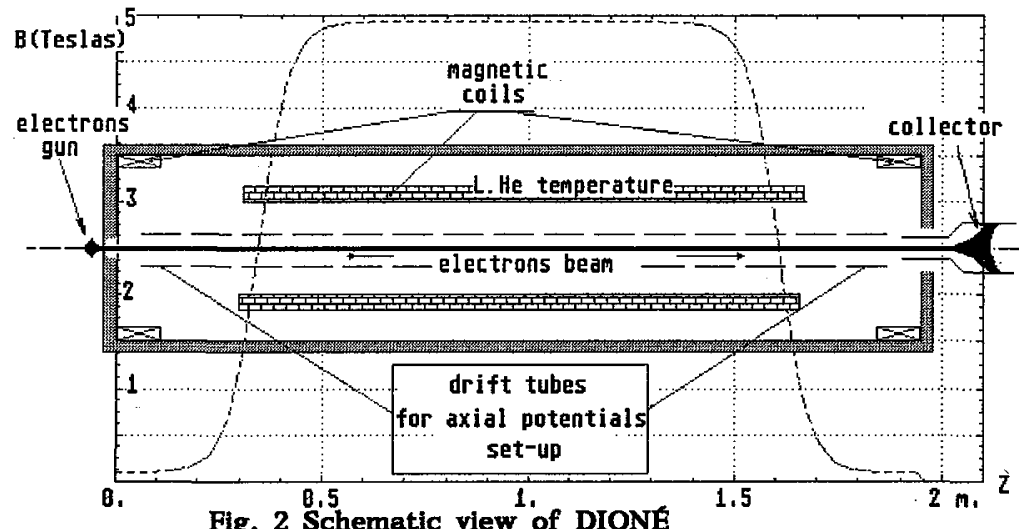

Different set of axial potentials are applied on the drift tubes according to the phase of the process : monocharged ions injection, confinement, extraction.

The $\mathrm{Li}^{1+}$ ions injected into DIONE, through the electron collector, are trapped by the electron beam and accumulated during the 200us EBIS injection time. The next phase ( confinement time necessary to ionize $\mathrm{Li}^{1+}$ into $\mathrm{Li}^{3+}$ by multiple electron collisions) is very short : according to the calculations, $3 \mathrm{~ms}$ are sufficient. Then the ions are expelled, producing a short pulse of charges.

Therefore many pulses could be acumulated in MIMAS during the $150 \mathrm{~ms}$ electron beam pulse duration. In fact the limitation comes from the DIONÉ ejected pulse duration (50us total width) too long for the MIMAS injection system and 8 pulses represent a maximum.

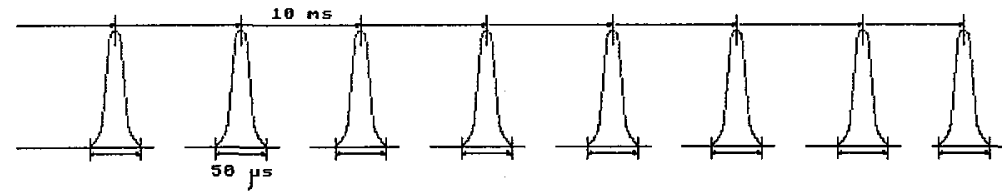

Fig. 3 Successive pulses with a separation of $10 \mathrm{~ms}$

According to the expected intensity of monocharged ions, DIONÉ should be able to deliver at least $20 \mu \mathrm{A}$ peak intensity pulses.

Moreover, the magnetic field value ( $5 \mathrm{Ts}$ ) is large enough to decouple the $1 \mathrm{~S}$ electron and nuclear spin. The magnetic field axis of the ioniser is parallel to the DIONE axis in order to avoid depolarization and a Wien filter provides the required spin direction for the accelerator. 


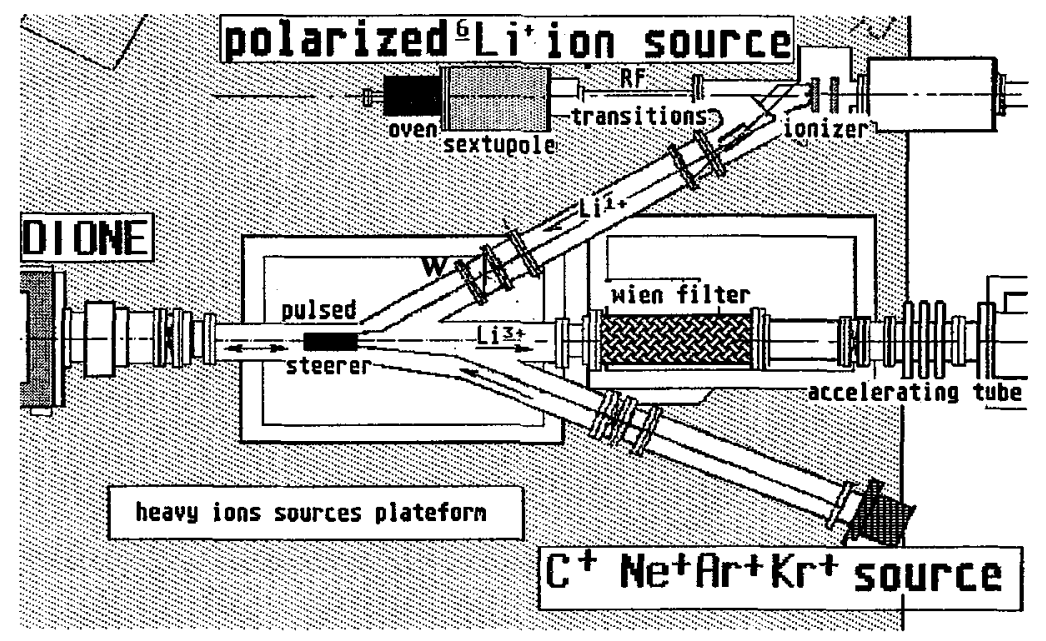

Fig. 4 Lithium plateform set-up

\section{Experimental results.}

1) Atomic beam and lonizer performances.

The Lithium oven worked satifactorily and a $35 \mu \mathrm{A} \mathrm{Li}{ }^{1+}$ beam has been obtained, as expected.

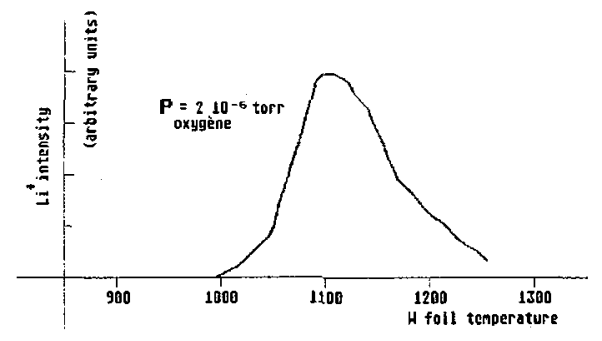

The Fig 5 shows the variation of the intensity versus tungsten foil temperature.

\section{2) Transmission to the EBIS collector.}

The transmission is poor : $7 \mu \mathrm{A}$ are injected into DIONE. The beam losses measurements point out that the $\mathrm{Li}^{1+}$ beam emittance is larger than the expected value, due to optical aberrations effect in the lonizer extracting region. The focusing system will be modified to improve the transmission.

\section{3 ) MIMAS and SATURNE tuning. Polarization measurements}

- 8 pulses of DIONE post-accelerated at $187.5 \mathrm{keV} / \mathrm{A}$ by a RFQ cavity are injected into MIMAS ring; the total injected charge is $4.10^{\circ} \mathrm{c}$; the intensity accelerated in MIMAS is $210^{9}$ charges, the efficiency of injection is $55 \%$, the optimum value is $70 \%$.

All the beam accelerated in MIMAS is transfered into SATURNE, giving $210^{9}$ charges $\left(710^{8}\right.$ particles) each acceleration cycle up to $750 \mathrm{Mev} / \mathrm{A}$.

- the polarization $\mathrm{P}_{z z}$ amounts to about of $70 \%$, measured at $187.5 \mathrm{keV} / \mathrm{A}$. The tensor polarization $\mathrm{P}_{z z}$ was measured in the $\mathrm{D}\left({ }^{6} \overrightarrow{\mathrm{Li}}, \boldsymbol{\alpha}\right){ }^{4} \mathrm{He}$ reaction at $\underline{0}_{j}^{\circ}$. The analysing power $\mathrm{A}_{\mathrm{yy}}\left({ }^{6} \mathrm{Li}\right)$ has been taken as equal to the known tensor analysing power $A_{y y}(\vec{d})$ of the ${ }^{6} \mathrm{Li}(\overline{\mathrm{d}}, \alpha){ }^{4} \mathrm{He}$ reaction at the same c.m. energy $\left(A_{y y}=0.444\right)$. 
These measurements are confirmed at $200 \mathrm{MeV} / \mathrm{A}$.

- Depolarizations. Two depolarization resonances can occur :

* the first one in MIMAS : $\nu_{z}=2-\gamma g\left(v_{z}=2.18\right)$

This line is pratically set on injection tuning $\left(\nu_{z}=2.19 ; \nu_{x}=2.22\right)$

Taking into account the low intensity $\left(<10^{10}\right.$ charges) there is no space

charge effect and a different vertical tuning is possible $\left(\nu_{z}=2.2\right)$.

* the second one in Saturne : $\gamma g=\nu_{z}-4$ occuring at $1125 \mathrm{Mev} / \mathrm{A}$ for $\nu_{z}=3.607$, also avoided by a different vertical tuning.

A four days physics experimental run with an excellent reliability has been achieved.

Conclusion

These first results are very encouraging and we hope to increase the number of particles by factor 3 and reach in future $10^{10}$ charges accelerated in Saturne.

\section{Acknowledgements}

We are especially indebted to P.Antoine, J.C.Ciret, L.Degueurce, B.Gastineau, P.Gros, P.Hulin, F.Harrault, P.Leaux, J.P.Pénicaud who contributed to the design and the achievement of the polarized $\mathrm{Li}^{\mathrm{it}}$ external ion source.

\section{References}

1) The source for a vector polarized lithium-6 beam at the Heidelberg En-Tandem

E.STEFFENS \& all N.I.M. 143 (1977) 409-421

2) Status report on DIONE

J.FAURE et al, International Symposium on E.B.I.S., Upton, N.Y.1988

Editor : Ady Hershcovitch B.N.L. 